\title{
Pemanfaatan Hidrofobik Deep Eutectic Solvents dalam Penyisihan Dimetoat, Klorpirifos, dan Profenofos pada Buah Tomat dan Sayur Brokoli
}

\section{Application Hydrophobic Deep Eutectic Solvents for Removal Dimethoat, Chlorpirifos, Profenofos from Tomato Fruit and Broccoli}

\author{
Axel Try Iddo Daely*, Renita Manurung \\ Departemen Teknik Kimia, Fakultas Teknik, Universitas Sumatera Utara \\ Jalan Almamater Kampus USU, Medan, 20155, Indonesia \\ *Email : axeldaely@yahoo.com
}

\begin{abstract}
Abstrak
Insektisida organofosfat adalah jenis pestisida yang umum digunakan, dimana dapat bersifat racun bagi organisme lingkungan tanaman bahkan kepada manusia. Hidrofobik Deep Eutectic Solvent (DES) merupakan pelarut nonpolar generasi baru dari pelarut ionik karena memiliki sifat fisik dan sifat kimia yang lebih baik sehingga dapat digunakan dalam proses ekstraksi. Dalam penelitian ini, DES disintesis pada suhu $50^{\circ} \mathrm{C}$ selama 15 menit dengan kecepatan pengadukan $300 \mathrm{rpm}$ dan rasio molar Dl-menthol: asam laurat divariasikan 1:1, 2:1, dan 3:1. Penyisihan pestisida dilakukan dengan mencampur $5 \mathrm{ml}$ DES dengan aquadest $200 \mathrm{ml}$ lalu buah Tomat dan sayur Brokoli dicuci dengan larutan tersebut. Karakteristik DES dilakukan dengan menganalisa wujud dan mengukur titik beku, densitas dan viskositas. Konsentrasi residu pestisida dianalisa menggunakan Gas Chromatography-Mass Spectrometer (GC-MS). Penyisihan pestisida tertinggi diperoleh dengan hidrofobik DES yang memiliki rasio molar $d l$-menthol : asam laurat adalah 3:1 dimana penyisihan pestisida tertinggi pada buah Tomat adalah 44,82\% untuk pestisida Dimetoat, $84,1 \%$ untuk pestisida Klorpirifos, dan 83,72\% untuk pestisida Profenofos dan pada sayur Brokoli adalah 35,19\% untuk pestisida Dimetoat, 64,64\% untuk pestisida Klorpirifos, dan 55,28\% untuk pestisida Profenofos.
\end{abstract}

Kata kunci: dimetoat, klorpirifos, profenofos, hidrofobik deep eutectic solvents, buah tomat, sayur brokoli

\begin{abstract}
Organophosphate insecticide is a type of pesticide that is commonly used, where this pesticide can be toxic to environmental organisms even to humans. Hydrophobic Deep Eutectic Solvent (DES) is a new generation nonpolar solvent of ionic liquids because it has better physical properties and chemical properties so that it can be used in the extraction process. DES was synthesized at $50{ }^{\circ} \mathrm{C}$ for 15 minutes with a stirring speed of $300 \mathrm{rpm}$ and a molar ratio of Dl-menthol: lauric acid varied from 1:1,2:1, and 3: 1 . Pesticide removal is done by mixing $5 \mathrm{ml}$ of DES with $200 \mathrm{ml}$ of aquadest and then Tomatoes and Broccoli vegetables are washed with the solution. DES characteristics are done by analyzing the shape and measuring the freezing point, density and viscosity of DES. The concentration of pesticide residues was analyzed using Gas Chromatography-Mass Spectrometer (GC-MS). The highest elimination of pesticides obtained with DES hydrophobic which has a molar ratio of dl-menthol: lauric acid is 3: 1 where the highest elimination of pesticides in Tomatoe is $44.82 \%$ for Dimethoate pesticide, $84.1 \%$ for Chlorpyrifos pesticide, and $83.72 \%$ for Profenofos pesticide and Broccoli $35.19 \%$ for Dimetoat pesticide, $64.64 \%$ for Chlorpyrifos pesticide, and $55.28 \%$ for Profenofos pesticides.
\end{abstract}

Keyword : dimethoate, chlorpyrifos, profenofos, hidrophobic deep eutectic solvents, tomato, broccoli

\section{Pendahuluan}

Sayur-sayuran dan buah-buahan merupakan sumber pangan yang dapat ditemukan dengan mudah dalam bahan pangan dan hampir selalu terdapat pada hidangan masyarakat Indonesia, baik dalam keadaan mentah (lalapan segar) atau setelah diolah menjadi makanan [1]. Salah satu metode yang terpenting untuk melindungi buah dan sayur dari organisme berbahaya, termasuk tumbuhan parasit, dan meningkatkan hasil pertanian adalah dengan menggunakan produk perlindungan tanaman seperti pestisida. Namun, produk perlindungan tanaman dapat memberikan efek merugikan pada produksi tanaman. Dampak merugikan dapat dirasakan langsung oleh penggunanya atau manusia, hewan dan lingkungan, terutama ketika dijual tanpa dilakukannya pengujian dan pengawasan [2]. 
Salah satu metode paling mudah dan murah dalam mengurangi kadar residu pestisida dalam hasil pertanian adalah dengan cara melakukan pencucian terhadap hasil panen pertanian. Proses pencucian buah dan sayur segar dengan air mengalir efektif mengurangi residu pestisida jenis fungisida sampai $89 \%$ tetapi untuk jenis herbisida hanya mampu mengurangi $38 \%$ [3]. Selain dengan metode pencucian, banyak usaha yang dilakukan untuk meminimalisir efek dari pestisida terhadap manusia dengan lingkungannya. Beberapa metode yang banyak digunakan adalah dengan penggunaan arang aktif sebagai adsorben dan ekstraksi menggunakan pelarut organik [4].

Deep Eutectic Solvent (DES) didefinisikan sebagai campuran dari dua atau lebih komponen, dapat itu cair atau solid dengan komposisi penurunan titik lebur yang tinggi menjadi satu cairan pada suhu kamar. DES terdiri dari senyawa organik yang berfungsi sebagai hdrogen bond donors (HBD) contohnya adalah amina, gula, alkohol, dan asam karboksilat yang dicampur dengan garam ammonium kuartener [5]. Teknologi ramah lingkungan merupakan isu ilmiah yang sangat penting saat ini. Kimia analitik ramah lingkungan mencakup pengembangan zat yang tidak berbahaya seperti pelarut, ekstraksi dan media reaksi. Penggunaan DES sebagai teknologi ramah lingkungan dalam proses ekstraksi sudah banyak dilakukan. Beberapa contoh penggunaan DES dalam proses ekstraksi adalah ekstraksi zat-zat organik seperti flavonoid, fenolik metabolit, dan pewarna alami dari beberapa jenis tumbuhan [6].

\section{Teori}

Pestisida

Pestisida secara harfiah berarti pembunuh hama. Pestisida pada umumnya adalah bahan kimia atau campuran bahan kimia serta bahanbahan lain (seperti ekstrak tumbuhan, mikroorganisme, dan lainnya) yang digunakan untuk mengendalikan organisme pengganggu tanaman/ tumbuhan (OPT) [7]. Pemakaian pestisida dalam pertanian berfungsi untuk mengendalikan serangga, jamur, dan gulma serta jenis hama lainnya yang dapat merusak produktivitas pertanian [8].

Insektisida organofosfat adalah insteksida yang mengandung unsur fosfat yang dihasilkan dari asam fosforik. Dahulu insteksida ini juga dikenal dengan nama fosfat organik (organic phosphate), insektisida fosfat (phosphorus insecticide), kerabat gas beracun (nerve gas relatives), dan ester asam fosfat (phosphotic acid esters) [9]. Organofosfat merupakan insektisida yang paling toksik diantara jenis pestisida lainnya dan sering menyebabkan keracunan pada manusia. Beberapa miligram organofosfat bahkan dapat menyebabkan kematian pada manusia jika termakan langsung [10]. Beberapa jenis insektisida organofosfat yang sering digunakan adalah Dimetoat, Klorpirifos, dan Profenofos.

\section{Deep Eutectic Solvents}

Hidrofobik DES adalah DES yang tidak dapat berikatan dengan air. DES jenis ini biasanya terdiri dari hydrogen bond donors (HBD) seperti asam lemak bebas, yang dicampur dengan hydrogen bond acceptors (HBA) seperti tetrabutilammonium klorid [5]. Hidrofobik DES memiliki sifat yang hampir sama dengan pelarut ionik, tetapi hidrofobik DES memiliki kelebihan yaitu lebih aman digunakan, komponen bahan baku yang lebih murah, dan dapat diperbarui. Sifat sukar larut hidrofobik DES juga memudahkan dalam proses ekstraksi cair-cair dengan efisiensi ekstraksi yang sangat baik [11].

Secara umum, DES dibuat dari garam berbasis ammonium ataupun phosponium. Garam tersebut dicampurkan dengan rasio yang berbedabeda dengan HBD nya seperti : alkohol, asam karboksilat, ester, eter, amida, nitrat, maupun asetat. Seperti yang telah dijelaskan sebelumnya, pembuatan DES sangat mudah dan cepat, dan tidak memerlukan pemurnian sama sekali. Proses pembuatan DES yang telah dilakukan adalah dengan menimbang HBD dan garam kuartener dan dimasukkan ke dalam sebuah wadah yang tertutup (hal ini disebabkan karena tingkat higroskopis bahan yang tinggi sehingga harus diisolasi dari uap air yang ada di udara), kemudian dilakukan pemanasan dan pengadukan hingga terbentuk cairan tidak berwarna (biasanya 2 jam pada $60^{\circ} \mathrm{C}$ ) [6].

\section{Metodologi Penelitian}

Bahan baku yang digunakan dalam penelitian ini adalah buah Tomat (Solanum lycopersicum) dan sayur Brokoli (Brassica oleracea) dari lahan pertanian Desa Ujung Sampun, Kecamatan Berastagi, Kabupaten Tanah Karo dan DES yang digunakan adalah DES berbasis Dl-Menthol $\left(\mathrm{C}_{10} \mathrm{H}_{20} \mathrm{O}\right)$ dengan asam laurat $\left(\mathrm{C}_{12} \mathrm{H}_{20} \mathrm{O}\right)$.

\section{Prosedur Penelitian}

DES disintesis dari Dl-Menthol $\left(\mathrm{C}_{10} \mathrm{H}_{20} \mathrm{O}\right)$ dengan asam laurat $\left(\mathrm{C}_{12} \mathrm{H}_{20} \mathrm{O}\right)$ yang dicampur dengan rasio molar tertentu $(1: 1,2: 1,3: 1)$ pada erlenmeyer yang dipanaskan di atas hot plate hingga mencapai suhu reaksi $50{ }^{\circ} \mathrm{C}$ dan dihomogenkan dengan kecepatan pengadukan $300 \mathrm{rpm}$ selama 15 menit dan didinginkan mencapai suhu kamar lalu dilakukan analisa densitas $(\rho)$, viskositas $(\mu)$, dan 
freezing point terhadap DES. Buah dan sayur segar yang diperoleh dari lahan pertanian dianalisa menggunakan gas chromatography-mass spectrometry (GC-MS) untuk mengetahui kadar pestisida sebelum pencucian. Buah dan sayur dicuci menggunakan DES yang telah dilarutkan dengan aquadest $200 \mathrm{ml}$ selama 1 menit. Setelah pencucian, buah dan sayur dipreparasi untuk dianalisa menggunakan GC-MS sehingga diketahui kadar pestisida setelah pencucian. Dibandingkan data yang diperoleh dengan konsentrasi pestisida bahan baku untuk memperoleh efisiensi penyisihan pestisida. Pada tabel 1 dapat dilihat Karakteristik DES yang dihasilkan dalam berbagai rasio molar pada suhu 30 ${ }^{\circ} \mathrm{C}$, sedangkan pada tabel 2 dapat dilihat konsentrasi pestisida pada bahan baku.

Tabel 1. Karakteristik DES yang dihasilkan dalam berbagai rasio molar pada suhu $30^{\circ} \mathrm{C}$

\begin{tabular}{|l|c|c|c|}
\hline $\begin{array}{c}\text { Rasio } \\
\text { Molar }\end{array}$ & $\begin{array}{c}\text { Wujud } \\
\text { DES }\end{array}$ & $\begin{array}{c}\text { Densitas } \\
\left(\mathbf{g} / \mathbf{c m}^{\mathbf{3}}\right)\end{array}$ & $\begin{array}{c}\text { Viskositas } \\
\mathbf{( c P )}\end{array}$ \\
\hline $1: 1$ & Bening & 0,8842 & 4,33 \\
\hline $2: 1$ & Bening & 0,8921 & 4,85 \\
\hline $3: 1$ & Bening & 0,9120 & 5,36 \\
\hline
\end{tabular}

Tabel 2. Konsentrasi pestisida pada bahan baku

\begin{tabular}{|c|c|c|}
\hline $\begin{array}{c}\text { Bahan } \\
\text { Baku }\end{array}$ & $\begin{array}{c}\text { Komponen } \\
\text { Penyusun }\end{array}$ & $\begin{array}{c}\text { Konsentrasi } \\
(\mathbf{m g} / \mathbf{k g})\end{array}$ \\
\hline \multirow{3}{*}{ Buah Tomat } & Dimetoat & 0,502 \\
\cline { 2 - 3 } & Klorpirifos & 2,678 \\
\cline { 2 - 3 } & Profenofos & 5,748 \\
\hline \multirow{2}{*}{$\begin{array}{c}\text { Sayur } \\
\text { Brokoli }\end{array}$} & Dimetoat & 0,827 \\
\cline { 2 - 3 } & Klorpirifos & 2,899 \\
\cline { 2 - 3 } & Profenofos & 5,892 \\
\hline
\end{tabular}

\section{Hasil}

Pengaruh Rasio Molar DES Terhadap Penyisihan Pestisida pada Buah Tomat

Pestisida organofosfat adalah pestisida yang mengandung unsur fosfat dan sangat umum digunakan. Semua pestisida organofosfat adalah bentuk ester dari asam fosfat, dimana gugus pestisida ini paling sensitif terhadap hidrolisis sehingga cepat terurai [7]. Hidrofobik DES adalah DES yang tidak dapat berikatan dengan air [8]. Hubungan antara rasio molar DES terhadap efisiensi penyisihan pestisida pada buah tomat dapat dilihat pada gambar 1 .

Pada gambar 1 penyisihan pestisida semakin meningkat berbanding lurus dengan rasio molar dl-menthol dan asam laurat di semua jenis pestisida, hal ini karena dengan semakin banyaknya DES ditambahkan, semakin banyak molekul yang membuat ikatan hidrogen dengan komponen polar dengan pestisida [5]. Polartitas dari DES adalah faktor penting dalam menentukan efisiensi ekstraksi yang dipengaurhi oleh interaksi antara zat terlarut (pestisida) dan DES. Hydrophobic DES yang disentesis bersifat non polar dan sukar larut dalam air [6] dan pestisida organofosfat yang diekstraksi bersifat non polar juga [9]. Berdasarkan sifat polaritas, molekul pestisida organofosfat yang bersifat non polar didistribusikan secara simteri dan berikatan dengan hydrophobic DES yang bersifat non polar juga sehingga penyisihan pestisida pada buah Tomat dapat berlangsung baik.

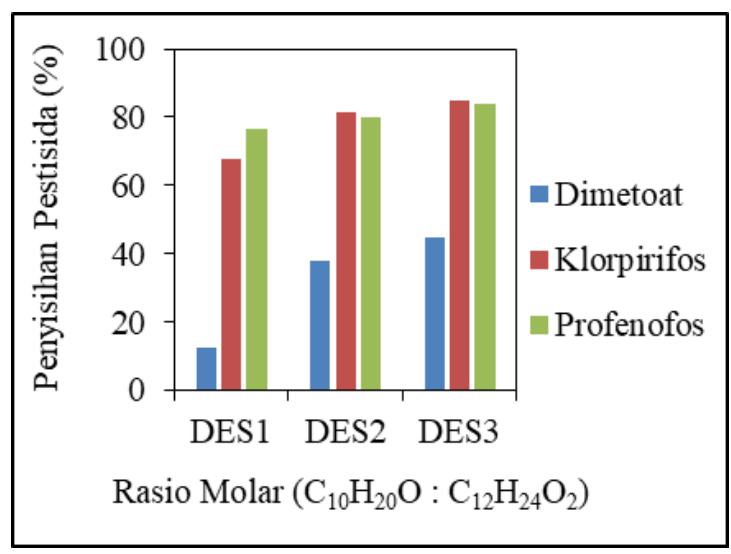

\section{Gambar 1. Pengaruh rasio molar terhadap penyisihan pestisida pada buah tomat}

\section{Pengaruh Rasio Molar DES Terhadap Penyisihan Pestisida pada Sayur Brokoli}

Konsentrasi awal ketiga jenis pestisida pada sayur Brokoli lebih banyak dibandingkan dengan buah Tomat. Menurut Alegantina., dkk., (2005) karakteristik tanaman yang permukaanya mempunyai malam (wax), sukar dibasahi, sehingga absorpsi pestisida lebih sukar dan deposit pestisidanya lebih sedikit dibandingkan tanaman yang tidak memiliki kulit seperti sayur [9]. Hubungan antara rasio molar DES terhadap efisiensi penyisihan pestisida (\%) pada sayur brokoli dapat dilihat pada gambar 2 .

Pada gambar 2 penyisihan pestisida semakin meningkat berbanding lurus dengan rasio molar $d l$-menthol dan asam laurat di semua jenis pestisida, hal ini karena dengan semakin banyaknya DES ditambahkan, semakin banyak molekul yang membuat ikatan hidrogen dengan komponen polar dengan pestisida [5]. Ketika semakin banyak hydrophobic DES yang bersifat non polar dan sukar larut dengan air, maka semakin banyak zat yang bersifat non polar dan mudah dihidrolisa dapat terekstrak oleh DES [6]. 


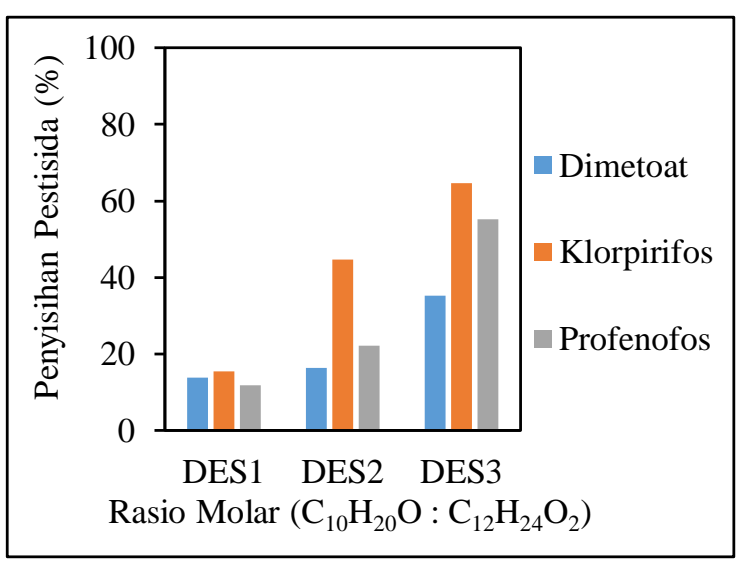

Gambar 2. Pengaruh rasio molar terhadap penyisihan pestisida pada sayur brokoli

Sama seperti dengan buah Tomat, diketahui jumlah rasio hydrophobic DES terhadap penyisihan ketiga pestisida pada sayur Brokoli berperan penting untuk mendapatkan \% penyisihan pestisida yang optimal dimana semakin tinggi rasio dl-menthol dan asam laurat maka semakin tinggi nilai penyisihan pestisida yang diperoleh karena hydrophobic DES bersifat non polar akan mengikat senyawa pestisida yang juga bersifat non polar.

\section{Kesimpulan}

Penyisihan pestisida tertinggi pada buah Tomat adalah $44,82 \%$ untuk pestisida Dimetoat, $84,1 \%$ untuk pestisida Klorpirifos, dan 83,72\% untuk pestisida Profenofos. Penyisihan pestisida ini diperoleh dengan hydrophobic DES yang memiliki rasio molar dl-menthol : asam laurat adalah 3:1.

Penyisihan pestisida tertinggi pada sayur Brokoli adalah 35,19\% untuk pestisida Dimetoat, 64,64\% untuk pestisida Klorpirifos, dan 55,28\% untuk pestisida Profenofos. Penyisihan pestisida ini diperoleh dengan hydrophobic DES yang memiliki rasio molar dl-menthol : asam laurat adalah 3:1, sehingga dapat disimpulkan bahwa hydrophobic DES berbasis Dl-Menthol dapat menyisihkan pestisida pada buah tomat dan sayur brokoli sangat baik.

\section{Ucapan Terima Kasih}

Penulis menyampaikan terima kasih kepada pengelola Laboratorium Pengujian Mutu dan Residu Pestisida BPTPH kota Medan yang telah memberikan hasil uji penelitian.

\section{Daftar Pustaka}

[1] I. Dewi, I. Mahardika, and M. Antara, "Residu Pestisida Golongan Organofosfat Komoditas Buah Cabai Merah pada Berbagai Lama Penyimpanan," J. Ilmu
Lingkung. Ecotrop., vol. 11, no. 1, pp. 3439, 2015.

[2] E. Szpyrka, A. Kurdziel, J. Rupar, and M. Słowik-Borowiec, "Pesticide residues in fruit and vegetable crops from the central and eastern region of Poland," Rocz. Państwowego Zakładu Hig., vol. 66, no. 2, pp. 107-113, 2015.

[3] B. R. Fitriadi and A. C. Putri, "MetodeMetode Pengurangan Residu Pestisida pada Hasil Pertanian," J. Rekayasa Kim. Lingkung., vol. 11, no. 2, p. 61, 2016.

[4] A. Rajan, S. Sreedharan, and B. V, "Solvent Extraction and Adsorption Technique for the Treatment of Pesticide Effluent," Civ. Eng. Urban Plan. An Int. J., vol. 3, no. 2, pp. 155165, 2016.

[5] K. Owczarek et al., "Natural deep eutectic solvents in extraction process," Chem. Chem. Technol., vol. 10, no. 4s, pp. 601606, 2016.

[6] E. L. Smith, A. P. Abbott, and K. S. Ryder, "Deep Eutectic Solvents (DESs) and Their Applications," Chem. Rev., vol. 114, no. 21, pp. 11060-11082, 2014.

[7] D. Sihombing, Skripsi Sarjana, Fakultas Kesehatan Masyarakat, Universitas Sumatera Utara, Medan, 2017.

[8] A. U and M. MF, "Pesticide Exposure and Human Health: A Review," J. Ecosyst. Ecography, vol. 01, no. s5, 2016, doi: 10.4172/2157-7625.s5-005.

[9] C. Maulidya, Tugas Akhir Diploma, Fakultas Matematika dan Ilmu Pengetahuan Alam, Universitas Sumatera Utara, Medan, 2016.

[10] F. Ngoula et al., "Effect of dimethoate (an organophosphate insecticide) on the reproductive system and fertility of adult male rat," Am. J. Pharmacol. Toxicol., vol. 9, no. 1, pp. 75-83, 2014.

[11] D. J. G. P. Van Osch, L. F. Zubeir, A. Van Den Bruinhorst, M. A. A. Rocha, and M. C. Kroon, "Hydrophobic deep eutectic solvents as water-immiscible extractants," Green Chem., vol. 17, no. 9, pp. 4518-4521, 2015. 